\title{
Mathematical Model of Influence Lines for Indeterminate Beams
}

\author{
Dr. Moujalli Hourani \\ Associate Professor \\ Department of Civil Engineering \\ Manhattan College \\ Riverdale, NY 10471
}

Abstract

The purpose of this paper is to present an improved and easy way for dealing with the influence lines for indeterminate beams. This paper describes the approach used to teach the topic of influence lines for indeterminate beams in the structural analysis and design courses, in the Civil Engineering Department at Manhattan College. This paper will present a simple method for teaching influence lines for indeterminate beams based on a mathematical model derived from the fundamental use of the flexibility method. The mathematical model is based on describing the forces and the deformations of the beam as mathematical functions related by consecutive integration processes.

Introduction

Many civil engineering students have difficulties dealing with the effects of live loads on structures because of the lack of knowledge of influence lines in general, and in particular, of the influence lines for indeterminate beams. These difficulties are perhaps due to the minimal amount of time spent on covering this very important topic in a structural analysis course, or due to unclear and confusing methods used to present the topic of influence lines. Several textbooks, ${ }^{1,2,3,4}$ cover the topic of influence lines, theories, examples dealing with determinate structures. Since these textbooks put little emphasis on indeterminate beams, this paper will focus on this topic. Two years ago, while the faculty of the Civil Engineering Department at Manhattan College, were conducting the assessment of the topics covered in the structural analysis courses, we found out that there was a great concern from our students about their capabilities to deal with influences lines for indeterminate beams. Based on the input from the students, we went back, and took another look at the way the topics of influence lines are being covered. Last year, the new approach was introduced in a structural analysis course, Advanced Structural Analysis II. At the end of the semester the student's assessments of the topic, showed a major improvement in their capabilities to solve problems of influence lines for indeterminate beams. After learning the new approach, the students were capable of developing their own computer programs using Excel/ Quattro, and Maple/MathCAD, to solve the problems of influence lines for multi-span beams with various boundary conditions. 
The approach presented in this paper is not based on new theories or principles, but rather on new methodology to solve a typical structural problem. The flexibility method, and the Conjugate- beam method have been used by others ${ }^{5,6}$ to construct the influence lines for indeterminate beams.

This paper will focus on describing a new approach adopted by the Civil Engineering Department at Manhattan College to teach and construct the influence lines for indeterminate beams. The new approach is easy to learn and program, but the mathematical manipulation required to obtain a symbolic solution can be too cumbersome. The topic of influence lines of indeterminate beams at Manhattan College is covered in a senior level elective course, "Advanced Structural Analysis II". The students enrolled in this course have already learned the analysis of indeterminate structures.

\section{The New Approach}

The mathematical model of influence lines for indeterminate beams presented in this paper is based on two fundamental principles that have been already covered in a previous structural analysis course. These two principles are outlined in the next section.

I- Flexibility Method

The flexibility method procedure adopted in this paper can be summarized as follows:

1- Determine the degree of static indeterminacy.

2- Choose the unknowns/redundants, name them $X_{1}, X_{2}, \ldots ., X_{n}$. [the redundant can be external reactions, internal forces or both] (Make sure that the structure remains stable).

3- Remove the redundants, i.e. set the unknowns equal to zero. The structure is now statically determinate, and it is called, the released structure ${ }^{7}$,

4- Remove all the loads and apply a unit load corresponding to $\mathrm{X}_{1}$, at the location of $\mathrm{X}_{1}$.

5- Repeat the process for all the X's.

6- Find the displacements corresponding to the unknowns in the released structure.

7- Find the flexibility coefficients.

8- Use the principle of superposition, and apply the compatibility conditions at the locations of all the redundants.

9- The equations developed by applying the compatibility conditions can be written in the form: $\{D O X i\}=\{D R X i\}+[F i j] *\{X i\}$

$\mathrm{DOX}_{\mathrm{i}}=$ the displacement corresponding to $\mathrm{X}_{\mathrm{i}}$ in the indeterminate beam.

$\mathrm{DRX}_{\mathrm{i}}=$ the displacement corresponding to $\mathrm{X}_{\mathrm{i}}$ in the determinate/ released beam.

$\mathrm{F}_{\mathrm{ij}} \quad=$ the displacement in the direction of $\mathrm{X}_{\mathrm{i}}$ at the location of $\mathrm{X}_{\mathrm{i}}$, due to a unit load applied in the direction of $\mathrm{X}_{\mathrm{j}}$ at the location of $\mathrm{X}_{\mathrm{j}}$.

\section{II- The Mathematical Model}

The mathematical model can be summarized as follows:

1 - Describe the load as a function $\mathbf{Y}_{\mathbf{L}}$ in the $\mathrm{X}-\mathrm{Y}$ coordinate system as shown in figure 1 . Since the influence line is based on applying a unit concentrated load, then, $\mathrm{Y}_{\mathrm{L}}=0$.

2 - The shear is equal to $\mathrm{Y}_{\mathrm{V}}=\mathrm{IY}_{\mathrm{L}} \mathrm{dx}=\mathrm{C}_{1}$

3 - The bending moment $\mathrm{Y}_{\mathrm{m}}=\mathrm{IY}_{\mathrm{v}} \mathrm{dx}=\mathrm{C}_{1} \mathrm{x}+\mathrm{C}_{2}$ 


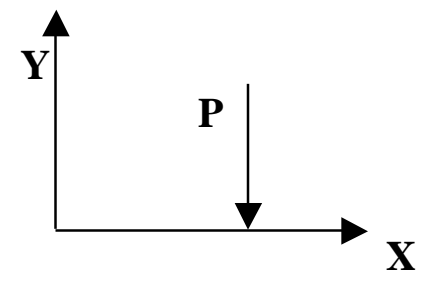

$\mathbf{Y}_{\mathrm{L}}=\mathbf{0}$

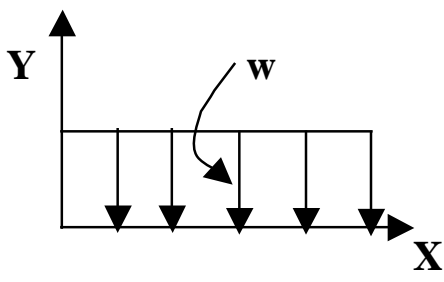

$\mathbf{Y}_{\mathbf{L}}=-\mathbf{w}$

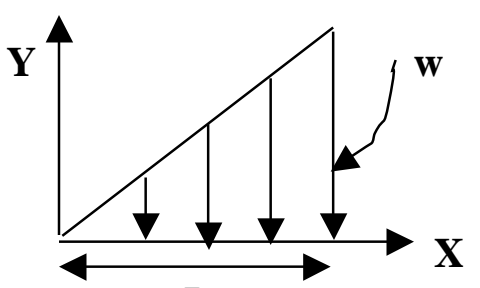

$\mathbf{L}$

$\mathbf{Y}_{\mathbf{L}}=(-\mathbf{X} / \mathbf{L}) * \mathbf{W}$

Figure 1. Description of the Load Function, $\mathrm{Y}_{\mathrm{L}}$

4 - The slope of the elastic curve is described by

$$
\mathrm{Y}_{\mathrm{s}}=\mathrm{I} 1 /(\mathrm{EI}) \mathrm{Y}_{\mathrm{m}} \mathrm{dx}=(1 / \mathrm{EI}) *\left(\mathrm{C}_{1} \mathrm{x}^{2} / 2+\mathrm{C}_{2} \mathrm{x}+\mathrm{C}_{3}\right)
$$

Assuming constant EI

5 - The transverse deflection of the beam is described by

$$
Y_{d}=(1 / E I) *\left(C_{1} x^{3} / 6+C_{2} x^{2} / 2+C_{3} x+C_{4}\right)
$$

The constants of integration can be determined by applying the geometric (slope, deflection, and compatibility conditions) and the loading (shear, moment, and joint equilibrium) boundary conditions. In this paper the derivation starts with the bending moment equation.

The procedure will be demonstrated in the next two examples, by developing the parametric solutions for the influence lines of the vertical reaction at an interior support of a twospan continuous beam, and the bending moment at a fixed end support of a propped cantilever. The equations of these two influence lines will be used in constructing the influence lines for any multi-span beam.

\section{Examples}

Example \# 1:

Draw the influence line for the vertical reaction at $B, R_{B}$, for the beam shown in figure E1.1. The beam is statically indeterminate to the first degree, choose as a redundant the vertical reaction at $\mathrm{B}, \mathrm{R}_{\mathrm{B}}=\mathrm{X}_{1}$.

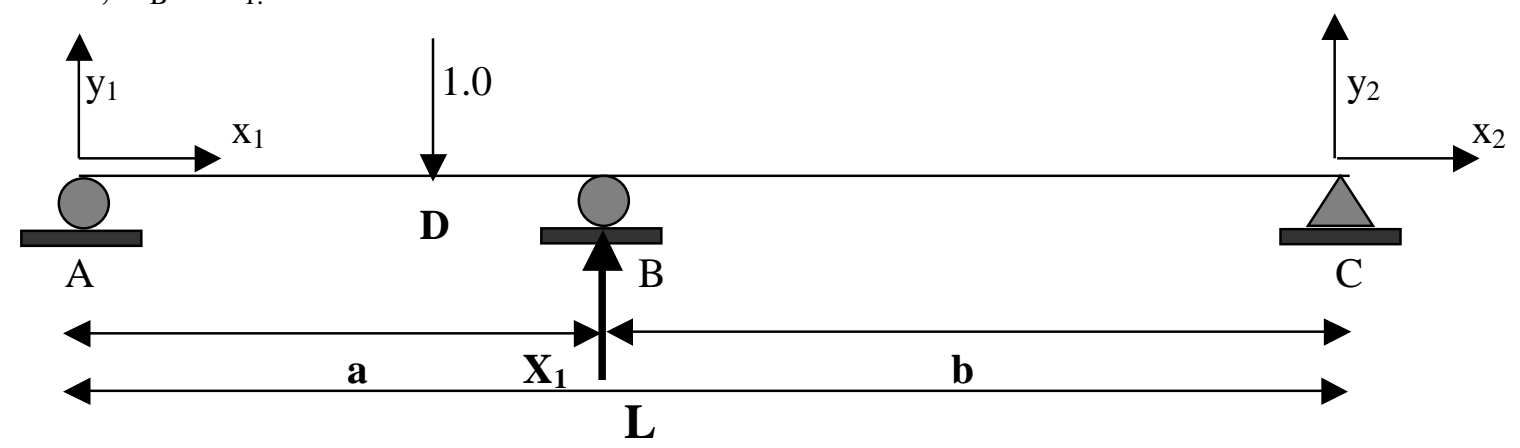

Figure E1.1. Two-span continuous beam 
Remove the redundant, the beam shown in figure E1.2. is statically determinate

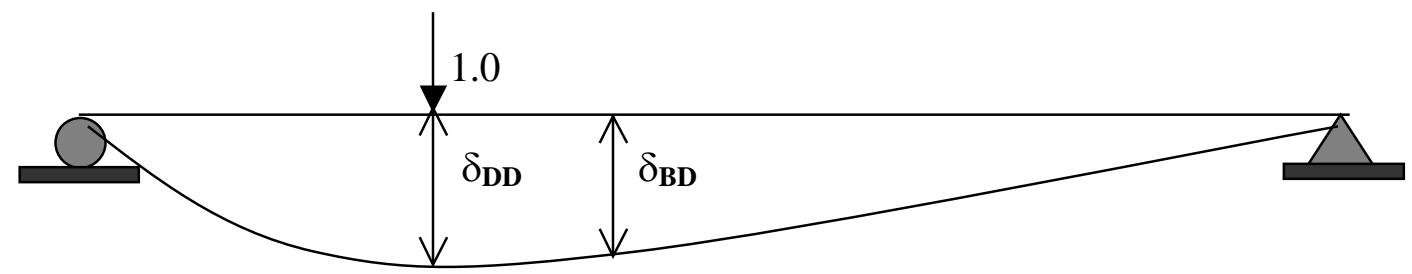

Figure E1.2. The released beam of example 1

Remove the applied load, and apply a unit vertical load at B, the virtual beam is shown in figure E1.3.

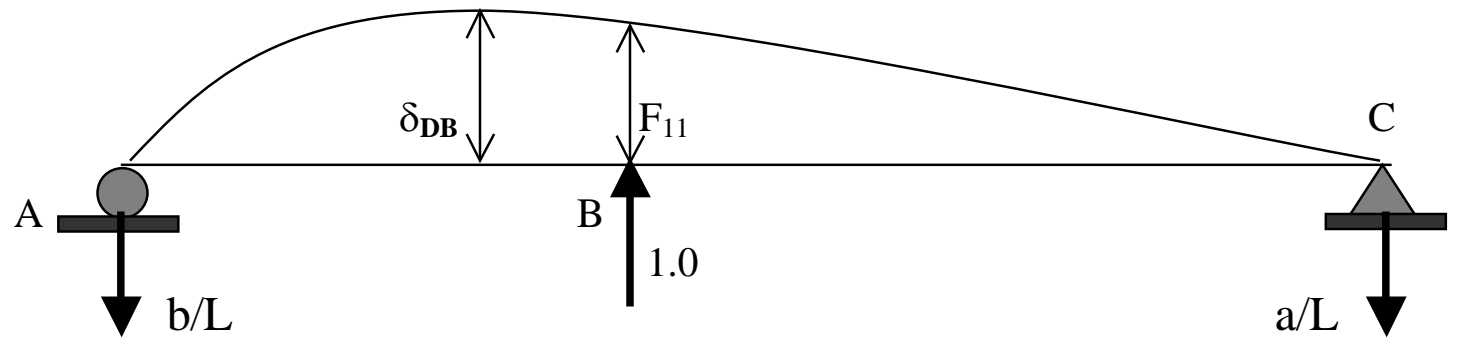

Figure E1.3. The virtual beam of example 1

Making use of the principle of superposition, the relationship between the three previous figures, can be summarized by:

Figure $($ E1.1 $)=$ Figure $(E 1.2)+$ Figure $(E 1.3) * \mathrm{X}_{1}$

Applying the compatibility condition for the vertical deflection at $\mathrm{B}$, gives

$0=-\delta_{\mathrm{BD}}+\mathrm{F}_{11} * \mathrm{X}_{1}$

Since we are dealing with a unit load in figures E1.2 \& E1.3, we can set $\delta_{\mathrm{BD}}=\delta_{\mathrm{DB}}$, and the reaction $\mathrm{R}_{\mathrm{B}}$, can be found from the above equation to be, $\mathrm{R}_{\mathrm{B}}=\mathrm{X}_{1}=\delta_{\mathrm{DB}} / \mathrm{F}_{11}$

As it can be seen from the above equation, the only figure needed is figure E1.3.

$\mathbf{X}_{1}=$ the vertical reaction at $\mathrm{B}$ due to a unit vertical load at any point $\mathrm{D}$ along the beam.

$\delta_{\mathbf{D B}}=$ the vertical displacement at $\mathrm{D}$ due to a unit vertical load at $\mathrm{B}$.

$\mathbf{F}_{11}=$ the vertical displacement at $\mathrm{B}$ due to a unit vertical load at B.

The moment diagram of the beam in figure E1.3 is drawn below.

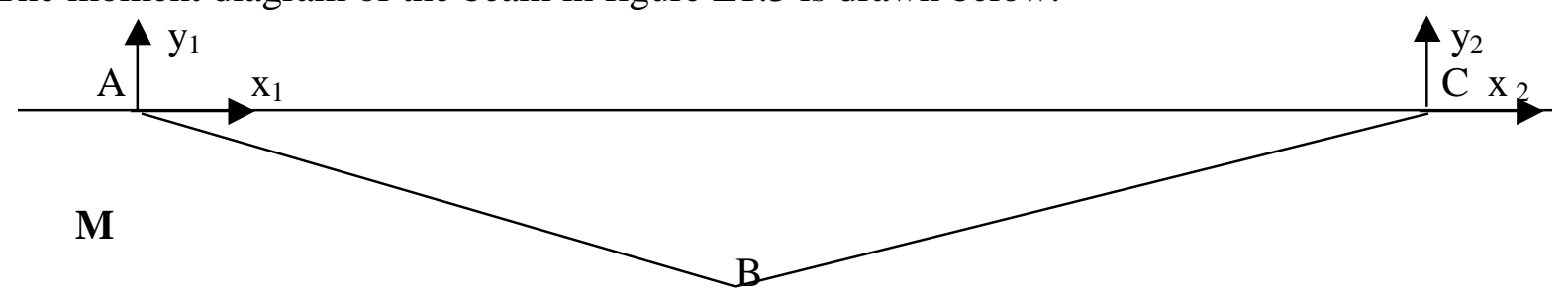

- $\mathbf{a b} / \mathbf{L}$

Figure E1.4. Moment diagram for the virtual beam

Due to the discontinuity in the moment diagram, the equations for the two segments $\mathrm{AB}$ and $\mathrm{BC}$ are needed to describe the moment functions. $\mathrm{x}_{1}-\mathrm{y}_{1}$ from $\mathrm{A}$ to $\mathrm{B}$, and $\mathrm{x}_{2}-\mathrm{y}_{2}$ from $\mathrm{C}$ to $\mathrm{B}$. 
From $A$ to $B$ (origin at $A$ )

$\left(\mathrm{y}_{\mathrm{m}}\right)_{1}=-(\mathrm{b} / \mathrm{L}) \mathrm{x}$

$\left(\mathrm{ys}_{\mathrm{S}}\right)_{1}=(1 / \mathrm{EI}) *\left[(-\mathrm{b} / \mathrm{L}) * \mathrm{x}^{2} / 2+\mathrm{C}_{3}\right]$

$\left(\mathrm{y}_{\mathrm{d}}\right)_{1}=(1 / \mathrm{EI}) *\left[(-\mathrm{b} / \mathrm{L}) * \mathrm{x}^{3} / 6+\mathrm{C}_{3} \mathrm{x}+\mathrm{C}_{4}\right]$
From C to B (origin at $C$ )

$\left(\mathrm{y}_{\mathrm{m}}\right)_{2}=(\mathrm{a} / \mathrm{L})^{*} \mathrm{x}$

$\left(\mathrm{y}_{\mathrm{s}}\right)_{2}=(1 / \mathrm{EI}) *\left[(\mathrm{a} / \mathrm{L}) * \mathrm{x}^{2} / 2+\mathrm{k}_{3}\right]$

$\left(\mathrm{y}_{\mathrm{d}}\right)_{2}=(1 / \mathrm{EI}) *\left[(\mathrm{a} / \mathrm{L}) * \mathrm{x}^{3} / 6+\mathrm{k}_{3} \mathrm{x}+\mathrm{k}_{4}\right]$

Apply the boundary conditions to find the constants of integration.

At $\mathrm{x}_{1}=0,\left(\mathrm{y}_{\mathrm{d}}\right)_{1}=0, \Rightarrow \mathbf{C}_{\mathbf{4}}=\mathbf{0} \quad$ At $\mathrm{x}_{2}=0,\left(\mathrm{y}_{\mathrm{d}}\right)_{2}=0 \Rightarrow \mathbf{k}_{\mathbf{4}}=\mathbf{0}$

The compatibility condition for the slope at $\mathrm{B}$, can be written as

$\left[\left(\mathrm{y}_{\mathrm{s}}\right)_{1}\right.$ at $\left.\mathrm{x}_{1}=\mathrm{a}\right]=\left[\left(\mathrm{y}_{\mathrm{s}}\right)_{2}\right.$ at $\left.\mathrm{x}_{2}=-\mathrm{b}\right]$, which gives

$-b^{*} a^{2} / 2 L+C_{3}=a^{*} b^{2} / 2 L+K_{3}$

Simplifying the above equation yields, $\mathbf{C}_{\mathbf{3}}-\mathbf{K}_{\mathbf{3}}=(\mathbf{a b} / \mathbf{2 L})^{*}(\mathbf{a}+\mathbf{b})=\mathbf{a b} / \mathbf{2}$

The compatibility condition for the vertical deflection at $\mathrm{B}$, can be written as

$\left[\left(\mathrm{y}_{\mathrm{d}}\right)_{1}\right.$ at $\left.\mathrm{x}_{1}=\mathrm{a}\right]=\left[\left(\mathrm{y}_{\mathrm{d}}\right)_{2}\right.$ at $\left.\mathrm{x}_{2}=-\mathrm{b}\right]$, which gives

$-b^{*} a^{3} / 6 L+C_{3} a=-a^{*} b^{3} / 6 L-K_{3} b$

Simplifying the above equation yields, $\mathbf{C}_{3} \mathbf{a}+\mathbf{K}_{3} \mathbf{b}=(\mathbf{a b} / \mathbf{6})^{*}(\mathbf{a}-\mathbf{b})$

Solving equations, (1) and (2) for $\mathrm{C}_{3}$ and $\mathrm{K}_{3}$, yield

\section{$\mathbf{C}_{3}=(\mathbf{a b} / \mathbf{6 L})(2 \mathrm{~b}+\mathbf{a})$ and $\mathrm{K}_{\mathbf{3}}=-(\mathbf{a b} / \mathbf{6 L})(\mathbf{b}+\mathbf{2 a})$}

Having solved for all the constants of integration, the equations describing the vertical displacement at any point along the beam due to a unit vertical load at $\mathrm{B}$ can be written as
$\left(\mathrm{y}_{\mathrm{d}}\right)_{1}=(1 / 6 \mathrm{EIL}) *\left[-\mathrm{b}^{*} \mathrm{x}^{3}+(\mathrm{a} * \mathrm{~b}) *(\mathrm{a}+2 \mathrm{~b}) \mathrm{x}\right]$
$0 \leq \mathrm{x} \leq \mathrm{a}$
$\left(\mathrm{y}_{\mathrm{d}}\right)_{2}=(1 / 6 \mathrm{EIL}) *\left[\mathrm{a}^{*} \mathrm{x}^{3}-(\mathrm{a} * \mathrm{~b}) *(2 \mathrm{a}+\mathrm{b}) \mathrm{x}\right]$
$-b \leq x \leq 0$

$\mathrm{y}_{\mathrm{d}}$ represents the vertical deflection at any point $\mathrm{D}$ due to a unit vertical load at $\mathrm{B}, \delta_{\mathbf{D B}}$.

$\mathbf{F}_{11}=\left(\mathbf{y}_{\mathbf{d}}\right)_{1}$ at $\mathbf{x}_{1}=\mathbf{a}, \mathrm{F}_{11}=(2 / 6 \mathrm{EIL}) *\left[\mathrm{a}^{2} \mathrm{~b}^{2}\right]$, and the vertical reaction at $\mathrm{B}, \mathrm{R}_{\mathrm{B}}$ can be written as,

$\mathrm{X}_{1}=\left(\mathrm{y}_{\mathrm{d}}\right)_{1} / \mathrm{F}_{11}=(1 / 6 \mathrm{EIL}) *\left[-\mathrm{bx}^{3}+\mathrm{x} *(\mathrm{ab})(\mathrm{a}+2 \mathrm{~b})\right] /\left[(2 / 6 \mathrm{EIL}) *\left(\mathrm{a}^{2} \mathrm{~b}^{2}\right)\right] 0 \leq \mathrm{x} \leq \mathrm{a}$

$\mathrm{X}_{1}=\mathbf{R}_{\mathbf{B}}=\left[-\mathrm{x}^{3}+\mathrm{x}^{*}\left(\mathrm{a}^{2}+2 \mathrm{ab}\right) /\left(2 * \mathrm{a}^{2} \mathrm{~b}\right)\right]$

$0 \leq \mathrm{x} \leq \mathrm{a}$

$\mathrm{X}_{1}=\mathbf{R}_{\mathbf{B}}=\left[\mathrm{x}^{3}-\mathrm{x}^{*}\left(2 \mathrm{ab}+\mathrm{b}^{2}\right] /\left(2 * \mathrm{~b}^{2} \mathrm{a}\right)\right]$

$-b \leq x \leq 0$

Knowing $R_{B}$, the others two reactions can be found by static equilibrium.

Summary

$\begin{array}{ll}\mathbf{0} \leq \mathbf{x}_{\mathbf{1}} \leq \mathbf{a} \quad(\text { origin at } \mathbf{A}) & -\mathbf{b} \leq \mathbf{x}_{\mathbf{2}} \leq \mathbf{0} \quad(\text { origin at } \mathbf{C}) \\ \left.\mathbf{R}_{\mathbf{A}}=\left[\mathrm{x}^{3}-\mathrm{x}^{*}\left(2 \mathrm{ab}+3 \mathrm{a}^{2}\right)+2^{*}\left(\mathrm{a}^{2} \mathrm{~L}\right)\right) /\left(2 * \mathrm{a}^{2} \mathrm{~L}\right)\right] & \mathbf{R}_{\mathbf{A}}=\left[\left(-\mathrm{x}^{3}(\mathrm{a} / \mathrm{b})+(\mathrm{ab}) * \mathrm{x}\right) /\left(2^{*}\left(\mathrm{a}^{2} \mathrm{~L}\right)\right)\right] \\ \mathbf{R}_{\mathbf{B}}=\left[\left(-\mathrm{x}^{3}+\mathrm{x}^{*}\left(\mathrm{a}^{2}+2 \mathrm{ab}\right)\right) /\left(2 *\left(\mathrm{a}^{2} \mathrm{~b}\right)\right)\right] & \mathbf{R}_{\mathbf{B}}=\left[\left(\mathrm{x}^{3}-\mathrm{x}^{*}\left(2 \mathrm{ab}+\mathrm{b}^{2}\right)\right) /\left(2 * \mathrm{~b}^{2} \mathrm{a}\right)\right] \\ \mathbf{R}_{\mathbf{C}}=\left[\mathrm{x}^{*}\left(\mathrm{x}^{2}-\mathrm{a}^{2}\right) /(2 \mathrm{abL})\right] & \mathbf{R}_{\mathbf{C}}=-\left[\left(\mathrm{x}^{3}-\mathrm{x}^{*}\left(2 \mathrm{ab}+3 \mathrm{~b}^{2}\right)-2 \mathrm{~b}^{2} \mathrm{~L}\right) /\left(2 \mathrm{~b}^{2} \mathrm{~L}\right)\right] \\ \mathbf{0} \leq \mathbf{x} \leq \mathbf{a} \quad(\text { origin at } \mathbf{A}) & \mathbf{a} \leq \mathbf{x} \leq \mathbf{L} \quad(\text { origin at } \mathbf{A}) \\ \mathbf{R}_{\mathbf{A}}=\left[\left(\mathrm{x}^{3}-\mathrm{x}^{*}\left(2 \mathrm{ab}+3 \mathrm{a}^{2}\right)+2^{*}\left(\mathrm{a}^{2} \mathrm{~L}\right)\right) /\left(2 * \mathrm{a}^{2} \mathrm{~L}\right)\right] & \mathbf{R}_{\mathbf{A}}=\left[\left(-(\mathrm{x}-\mathrm{L})^{3}(\mathrm{a} / \mathrm{b})+(\mathrm{ab}) *(\mathrm{x}-\mathrm{L})\right) /\left(2 * \mathrm{a}^{2} \mathrm{~L}\right)\right] \\ \mathbf{R}_{\mathbf{B}}=\left[\left(-\mathrm{x}^{3}+\mathrm{x}^{*}\left(\mathrm{a}^{2}+2 \mathrm{ab}\right)\right) /\left(2 * \mathrm{a}^{2} \mathrm{~b}\right)\right] & \mathbf{R}_{\mathbf{B}}=\left[\left((\mathrm{x}-\mathrm{L})\left(\mathrm{x}^{2}-2 \mathrm{Lx}+\mathrm{a}^{2}\right)\right) /\left(2 * \mathrm{~b}^{2} \mathrm{a}\right)\right] \\ \mathbf{R}_{\mathbf{C}}=\left[\left(\mathrm{x}^{*}\left(\mathrm{x}^{2}-\mathrm{a}^{2}\right)\right) /(2 \mathrm{abL})\right] & \mathbf{R}_{\mathbf{C}}=\left[\left(-\mathrm{x}^{3}+3 \mathrm{Lx} x^{2}+\mathrm{ax} *(\mathrm{a}-4 \mathrm{~L})+\mathrm{a}^{2} \mathrm{~L}\right) /\left(2 \mathrm{~b}^{2} \mathrm{~L}\right)\right]\end{array}$

These equations are used to determine the internal resisting forces at any point in the beam. The equations of the reactions, and the shear and bending moment have been implemented into a spreadsheet computer program capable of determining the placement of the live load, and the magnitude of the reaction and the internal resisting forces. A sample of the spreadsheet program is shown below. The program has more capabilities than what is presented in this paper. 
THE INPUT IS RESTRICTED TO THE HIGHLIGHTED BOXED CELLS.

$$
\begin{aligned}
& \mathrm{L}=56 \quad \mathrm{a}=24 \quad \mathrm{~b}=2 \\
& \mathrm{EI}=1
\end{aligned}
$$

$\mathrm{M}_{1}$ is the bending moment in span 1 at a distance $\mathrm{X}_{1}$ from $\mathrm{A}$.

$\mathrm{M}_{2}$ is the bending moment in span 2 at a distance $\mathrm{X}_{2}$ from $\mathrm{A}$.

In span1 the moment is maximum at $\mathrm{X}$ between

INFLUENCE LINE FOR $\mathrm{M}_{1} \mathrm{AT}_{1}=$

\begin{tabular}{|cc}
\hline 10 & 12 \\
\hline 36.8 & \\
40 & 40 \\
\hline
\end{tabular}

\begin{tabular}{|c|c|c|c|c|c|c|c|}
\hline STATION & $\mathbf{X}$ & RA & $\mathbf{R B}$ & $\mathbf{R C}$ & CHECK & M1 & M2 \\
\hline 1 & 0.00 & 1.000 & 0.000 & 0.000 & 1 & 0.000 & 0.000 \\
\hline 2 & 2.40 & 0.879 & 0.137 & -0.016 & 1 & 1.188 & -0.255 \\
\hline 3 & 4.80 & 0.759 & 0.272 & -0.031 & 1 & 2.389 & -0.494 \\
\hline 4 & 7.20 & 0.642 & 0.402 & -0.044 & 1 & 3.615 & -0.702 \\
\hline 5 & 9.60 & 0.528 & 0.526 & -0.054 & 1 & 4.880 & -0.864 \\
\hline 6 & 12.00 & 0.420 & 0.641 & -0.060 & 1 & 4.196 & -0.964 \\
\hline 7 & 14.40 & 0.318 & 0.744 & -0.062 & 1 & 3.177 & -0.987 \\
\hline 8 & 16.80 & 0.224 & 0.834 & -0.057 & 1 & 2.235 & -0.918 \\
\hline 9 & 19.20 & 0.138 & 0.908 & -0.046 & 1 & 1.383 & -0.741 \\
\hline 10 & 21.60 & 0.063 & 0.964 & -0.027 & 1 & 0.634 & -0.440 \\
\hline 11 & 24.00 & 0.000 & 1.000 & 0.000 & 1 & 0.000 & 0.000 \\
\hline 12 & 27.20 & -0.065 & 1.014 & 0.051 & 1 & -0.651 & 0.818 \\
\hline 13 & 30.40 & -0.110 & 0.992 & 0.118 & 1 & -1.097 & 1.883 \\
\hline 14 & 33.60 & -0.136 & 0.938 & 0.198 & 1 & -1.360 & 3.168 \\
\hline 15 & 36.80 & -0.146 & 0.856 & 0.290 & 1 & -1.463 & 4.645 \\
\hline 16 & 40.00 & -0.143 & 0.750 & 0.393 & 1 & -1.429 & 6.286 \\
\hline 17 & 43.20 & -0.128 & 0.624 & 0.504 & 1 & -1.280 & 4.864 \\
\hline 18 & 46.40 & -0.104 & 0.482 & 0.622 & 1 & -1.040 & 3.552 \\
\hline 19 & 49.60 & -0.073 & 0.328 & 0.745 & 1 & -0.731 & 2.322 \\
\hline 20 & 52.80 & -0.038 & 0.166 & 0.872 & 1 & -0.377 & 1.147 \\
\hline 21 & 56.00 & 0.000 & 0.000 & 1.000 & 1 & 0.000 & 0.000 \\
\hline
\end{tabular}

In span2 the moment is maximum at $\mathrm{X}$ between
INFLUENCE LINE FOR $\mathrm{M}_{2} \mathrm{AT} \mathrm{X}_{2}=$

Figure E1.5. Spreadsheet input and output for example 1. 


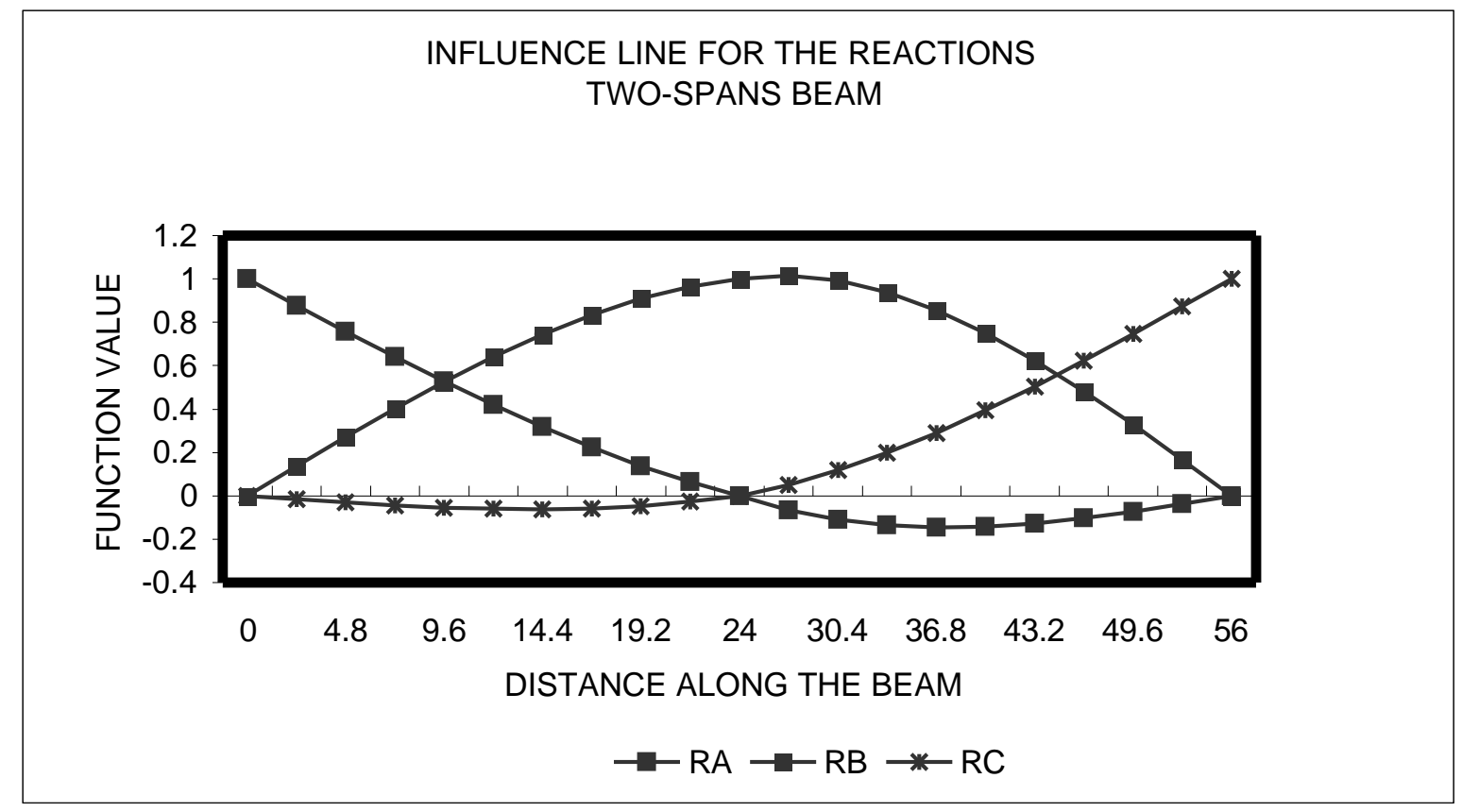

Figure E1.6. Graphical representation of the reactions of example 1

Example \#2:

Draw the influence line for bending moment at $\mathrm{A}, \mathrm{M}_{\mathrm{A}}$, of the propped cantilever beam shown in figure E2.1. The beam is statically indeterminate to the first degree, choose the bending moment at $\mathrm{A}$, as the redundant, $\mathrm{X}_{1}=\mathrm{M}_{\mathrm{A}}$

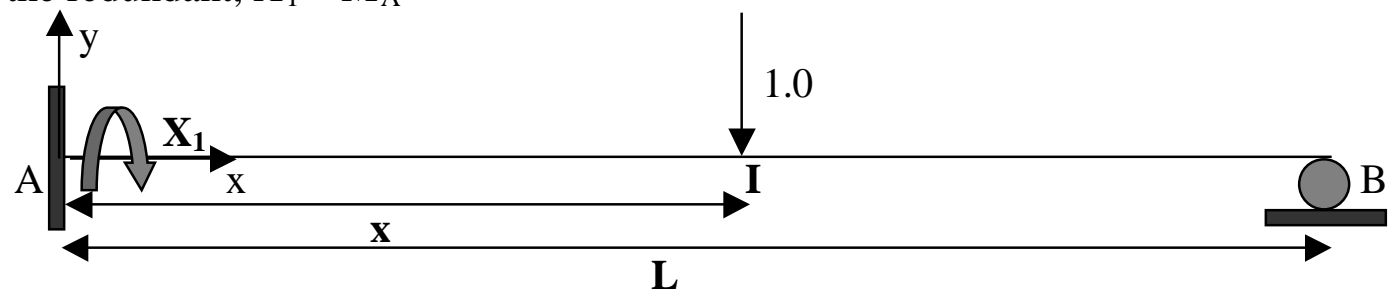

Figure E2.1. Propped cantilever beam

Remove the redundant, now, the beam is statically determinate as shown in figure E2.2.

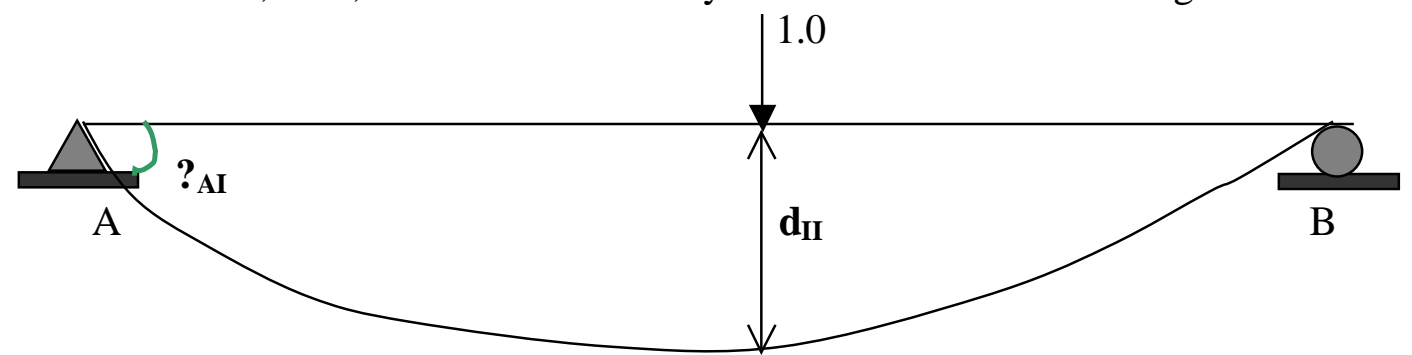

Figure E2.1. The released beam for example 2

Proceeding of the 2002 American Society for Engineering Education Annual Conference \& Exposition Copyright (C) 2002, American Society for Engineering Education 
Remove the applied load, and apply a unit bending moment at A, the virtual beam is shown in figure E2.3.

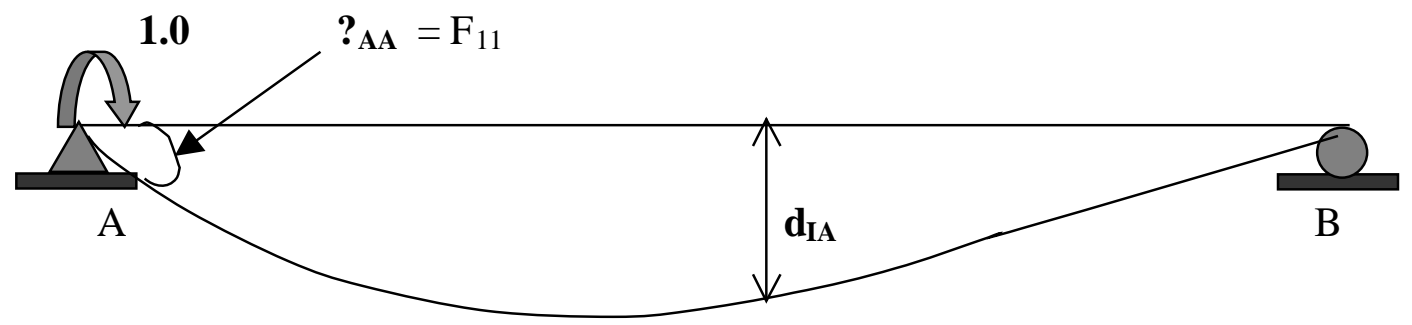

Figure E2.3. The virtual beam of example 2

Making use of the principle of superposition, the relationship between the three pervious figures, can be represented by: Figure $(E 2.1)=$ Figure $(E 2.2)+$ Figure $(E 2.3) * \mathrm{X}_{1}$

Applying the compatibility condition for the slope at $\mathrm{A}$, we get

$\left(?_{\mathrm{A}}\right)_{1}=\left(?_{\mathrm{A}}\right)_{2}+\left(?_{\mathrm{A}}\right)_{3} * \mathrm{X}_{1}$, or, $0=\left(?_{\mathrm{AI}}\right)+\mathrm{F}_{11} * \mathrm{X}_{1}$

Applying the Maxwell's law of reciprocal deflections in figures E2.2 \& E2.3, set

$\boldsymbol{?}_{\mathrm{AI}}=\mathbf{d}_{\mathrm{IA}}$. From which

$\mathrm{X}_{1}=-\mathrm{d}_{\mathrm{IA}} / \mathrm{F}_{11}$

It can be seen from the above equation that the only figure needed is figure E2.3

$\mathbf{X}_{1}=$ the bending moment at A due to a unit vertical load at any point I along the beam.

$\boldsymbol{?}_{\mathrm{AI}}=$ the rotation at $\mathrm{A}$ due to a unit vertical load at $\mathrm{I}$.

$\mathbf{d}_{\mathbf{I A}}=$ the vertical deflection at I due to a unit bending moment at $\mathrm{A}$.

$\mathbf{F}_{\mathbf{1 1}}=$ the rotation at $\mathrm{A}$ due to a unit bending moment at $\mathrm{A}$.

The moment diagram for the beam in figure E2.3 is drawn in figure E2.4.

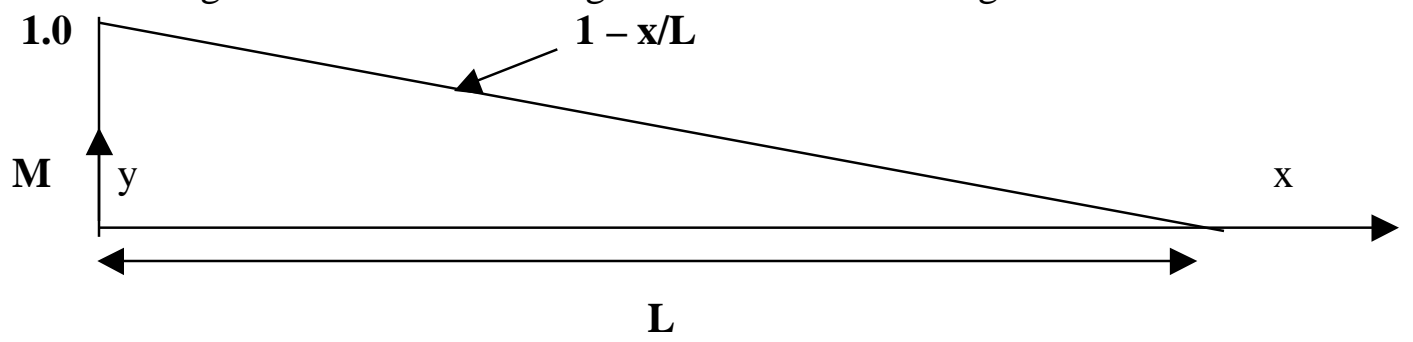

Figure E2.4. The moment diagram for the beam in figure E2.3

$\left(\mathrm{y}_{\mathrm{m}}\right)=1-\mathrm{x} / \mathrm{L}$

$\mathrm{y}_{\mathrm{S}}=(1 / \mathrm{EI}) *\left(-\mathrm{x}^{2} / 2 \mathrm{~L}+\mathrm{x}+\mathrm{C}_{3}\right)$

$y_{d}=(1 / E I) *\left(-x^{3} / 6 L+x^{2} / 2+C_{3} x+C_{4}\right)$

Apply the boundary conditions to find the constants of integration.

At $\mathrm{x}=\mathrm{a}, \mathrm{y}_{\mathrm{d}}=0$, then, $\mathbf{C}_{\mathbf{4}}=\mathbf{0}$

At $\mathrm{x}=\mathrm{L}, \mathrm{y}_{\mathrm{d}}=0$, then, $\mathbf{C}_{\mathbf{3}}=\mathbf{-} \mathbf{L} / \mathbf{3}$

Now, rewrite the equations for the slope and the deflection.

$\mathrm{y}_{\mathrm{S}}=(1 / 6 \mathrm{EIL}) *\left(-3 \mathrm{x}^{2}+6 \mathrm{xL}-2 \mathrm{~L}^{2}\right)$

$\mathrm{y}_{\mathrm{d}}=(1 / 6 \mathrm{EIL}) *\left(-\mathrm{x}^{3}+3 \mathrm{x}^{2} \mathrm{~L}-2 \mathrm{~L}^{2} \mathrm{x}\right)$

The slope at $\mathrm{x}=0$ is equal to $\mathrm{F}_{11}=-\mathrm{L} / 3 \mathrm{EI}$

$\mathrm{y}_{\mathrm{d}}$ represents the vertical deflection at any point I due to a unit bending moment at $\mathrm{A}, \mathbf{d}_{\text {IA. }}$.

Proceeding of the 2002 American Society for Engineering Education Annual Conference \& Exposition

Copyright $\odot$ 2002, American Society for Engineering Education 
$\mathbf{X}_{\mathbf{1}}=\mathbf{M}_{\mathrm{A}}=-\mathbf{d}_{\mathbf{I A}} / \mathbf{F}_{\mathbf{1 1}}=\left(-\mathrm{x}^{3}+3 \mathrm{Lx}^{2}-2 \mathrm{~L}^{2} \mathrm{x}\right) /\left(2 \mathrm{~L}^{2}\right)$

$M_{A}$ is maximum when $x=.422649 \mathrm{~L} .\left(M_{A}\right)_{\max }=-.19250 \mathrm{~L}$

The other reactions can be found by static equilibrium, and they are described below. $\mathbf{R}_{\mathbf{A}}=\left(\mathrm{x}^{3}-3 \mathrm{Lx} \mathrm{x}^{2}+2 \mathrm{~L}^{3}\right) /\left(2 \mathrm{~L}^{3}\right)$, and $\mathbf{R}_{\mathbf{B}}=\left(-\mathrm{x}^{3}+3 \mathrm{x}^{2} \mathrm{~L}\right) /\left(2 \mathrm{~L}^{3}\right)$.

Having derived the equation for the vertical reaction of the internal support for the twospan beam in example1, and the equation for the bending moment at the fixed end of the propped cantilever in example 2, these equations will be used in the solution of any indeterminate multispan beam. The next two examples will demonstrate the use of these equations in developing the solutions for two continuous beams with different support conditions.

Example \#3:

Derive the equations of the influence lines for the reactions of three-span continuous prismatic beam shown in figure E3.1.

The beam is statically indeterminate to the second degree, choose as redundants the vertical reactions at $\mathrm{B}$ and $\mathrm{C}$, where $\mathrm{R}_{\mathrm{B}}=\mathrm{X}_{1}$, and $\mathrm{R}_{\mathrm{C}}=\mathrm{X}_{2}$.

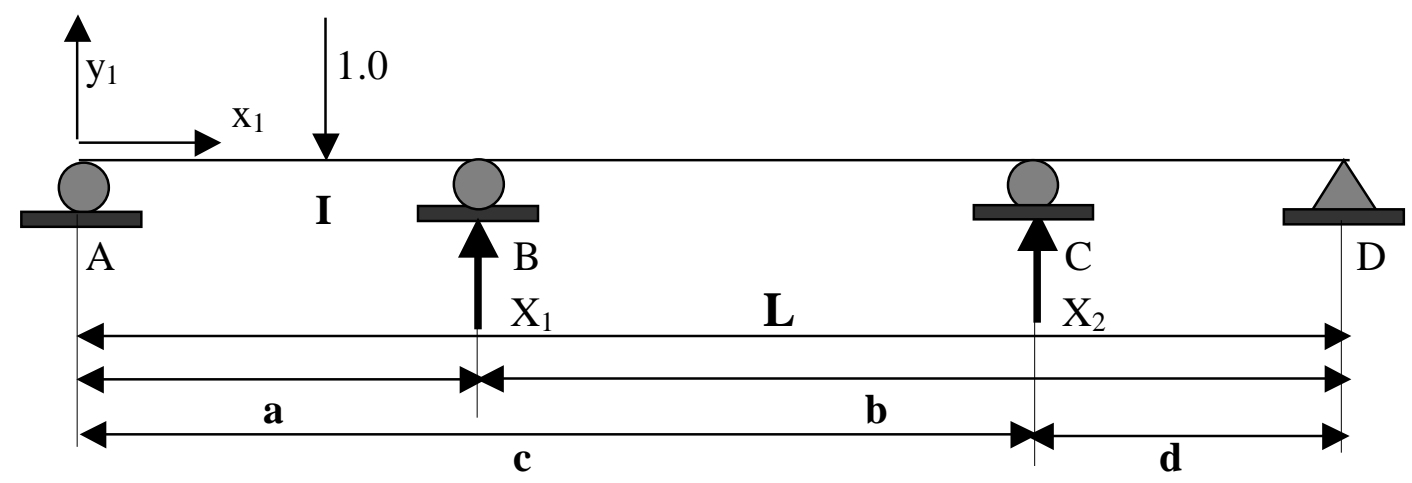

Figure E3.1. Three-span prismatic beam

Remove the redundants, now, the beam is statically determinate as shown in figure E3.2.

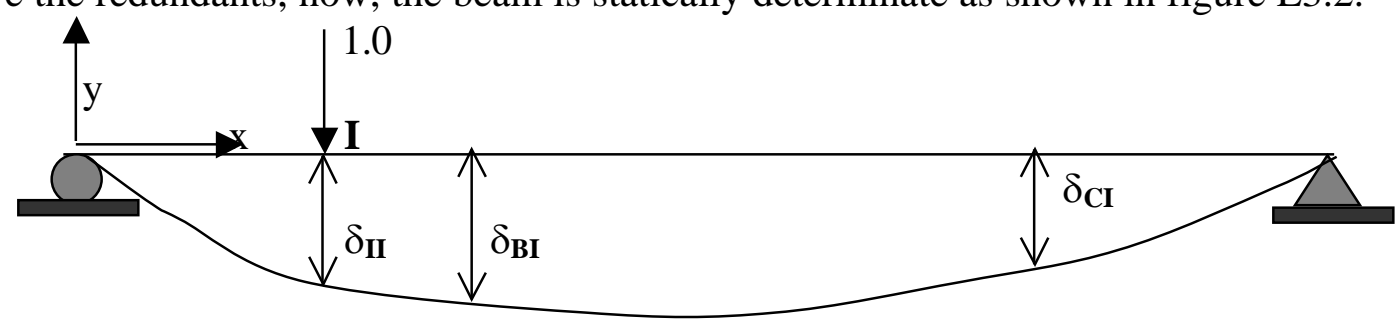

Figure E3.2. The released beam of example 3

Remove the applied load, and apply a unit vertical load at B, as shown in figure E3.3. 


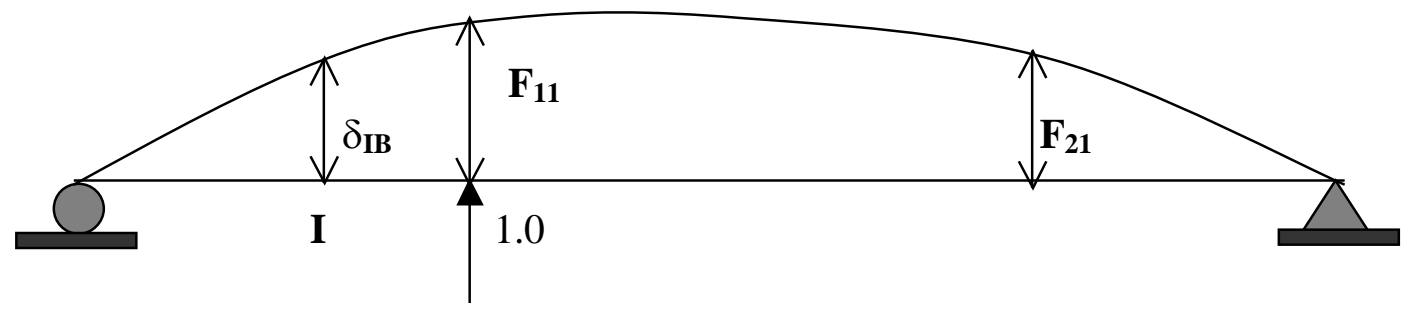

Figure E3.3. The virtual beam loaded by a unit vertical load at B

Figure E3.4 shows the virtual beam loaded by a unit vertical load at C.

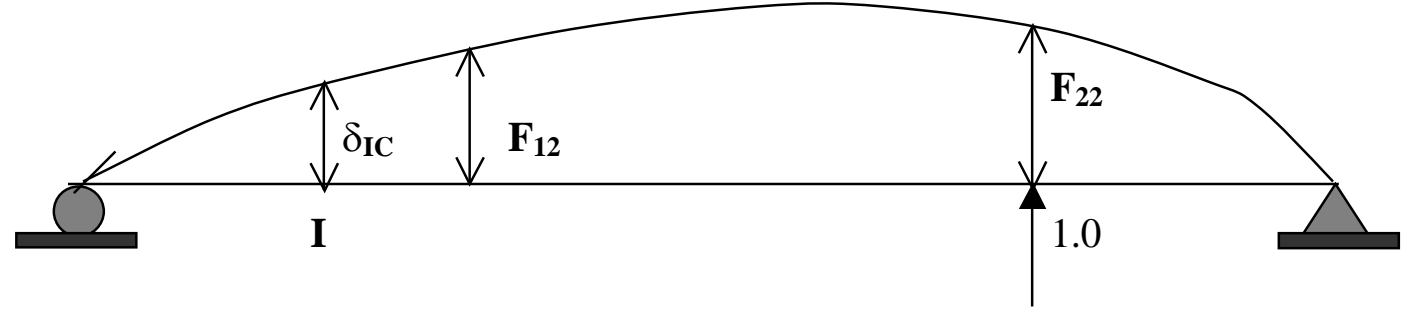

Figure E3.4. The virtual beam loaded by a unit vertical load at $\mathrm{C}$

Making use of the principle of superposition, the relationship between the four previous figures can be represented by: Figure $(E 3.1)=$ Figure $(E 3.2)+$ Figure $(E 3.3) * \mathrm{X}_{1}+$ Figure (3.4)* $\mathrm{X}_{2}$ Applying the compatibility conditions for the vertical displacements at $\mathrm{B}$ and $\mathrm{C}$ respectively, yield the equations shown below.

$0=-\delta_{\mathrm{BI}}+\mathrm{F}_{11} \mathrm{X}_{1}+\mathrm{F}_{12} * \mathrm{X}_{2}$

$0=-\delta_{\mathrm{CI}}+\mathrm{F}_{21} \mathrm{X}_{1}+\mathrm{F}_{22} * \mathrm{X}_{2}$

Since we are dealing with unit load in figures E3.2, E3.3 and E3.4, we can set $\delta_{\mathbf{B I}}=\delta_{\mathbf{I B}}, \delta_{\mathbf{C I}}=$ $\delta_{\text {IC }}$, and $\mathrm{F}_{12}=\mathrm{F}_{21}$.

In a matrix form, the above two equations can be represented by:

$$
\left[\begin{array}{ll}
F_{11} & F_{12} \\
F_{12} & F_{22}
\end{array}\right] \quad\left\{\begin{array}{l}
X_{1} \\
X_{2}
\end{array}\right\}=\left\{\begin{array}{l}
\delta_{I B} \\
\delta_{I C}
\end{array}\right\}
$$

$\mathrm{F}_{11}=$ vertical displacement at $\mathrm{B}$ due to a unit vertical load at $\mathrm{B}$.

$\mathrm{F}_{22}=$ vertical displacement at $\mathrm{C}$ due to a unit vertical load at $\mathrm{C}$.

$\mathrm{F}_{12}=$ vertical displacement at $\mathrm{B}$ due to a unit vertical load at $\mathrm{C}$.

$\mathrm{F}_{21}=$ vertical displacement at $\mathrm{C}$ due to a unit vertical load at $\mathrm{B}$.

$\delta_{\mathrm{IB}}=$ vertical displacement at any point I along the beam due to a unit vertical load at $\mathrm{B}$.

$\delta_{\mathrm{IC}}=$ vertical displacement at any point I along the beam due to a unit vertical load at $\mathrm{C}$.

The parametric values of the above terms have been determined in the formulation of the influence line for $\mathrm{R}_{\mathrm{B}}$, for two-span beam presented in example 1 .

$\mathrm{F}_{11}=\mathbf{2} * \mathbf{a}^{2} \mathbf{b}^{2} /(6 \mathrm{EIL}), \mathrm{F}_{22}=\mathbf{2} * \mathbf{c}^{2} \mathbf{d}^{2} /(6 \mathrm{EIL}), \mathrm{F}_{21}=\mathrm{F}_{12}=\left[\mathbf{a}^{*}(\mathbf{c}-\mathbf{L}) *\left(\mathbf{c}^{2}-\mathbf{2 c L}+\mathbf{a}^{2}\right)\right] /(6 \mathrm{EIL})$

$\left(\delta_{\mathbf{B I}}\right)_{1}=$ the vertical displacement at $\mathrm{B}$ due to a unit load at I, where, I is located anywhere between $\mathrm{A}$ and $\mathrm{B}$.

$\left(\delta_{\text {IB }}\right)_{1}=\left(-\mathrm{bx}^{3}+\mathrm{ab} * \mathrm{x} *(\mathrm{a}+2 \mathrm{~b})\right) /(6 \mathrm{EIL}) \quad 0 \leq \mathrm{x} \leq \mathrm{a}$

Proceeding of the 2002 American Society for Engineering Education Annual Conference \& Exposition Copyright (C) 2002, American Society for Engineering Education 
$\left(\delta_{\mathbf{B I}}\right)_{2}=$ the vertical displacement at B due to a unit load at I, where, I is located anywhere between $\mathrm{B}$ and $\mathrm{D}$.

$\left(\delta_{\mathbf{I B}}\right)_{2}=\left[\mathrm{a}^{*}(\mathrm{x}-\mathrm{L})^{*}\left(\mathrm{x}^{3}+-2 \mathrm{xL}+\mathrm{a}^{2}\right)\right] /(6 \mathrm{EIL}) \quad \mathrm{a} \leq \mathrm{x} \leq \mathrm{L}$

$\left(\delta_{\mathbf{C I}}\right)_{1}=$ the vertical displacement at $\mathrm{C}$ due to a unit load at $\mathrm{I}$, where, $\mathrm{I}$ is located anywhere between $\mathrm{A}$ and $\mathrm{C}$.

$\left(\delta_{\text {IC }}\right)_{1}=\left[-\mathrm{dx}^{3}+\mathrm{cd} * \mathrm{x}^{*}(\mathrm{c}+2 \mathrm{~d})\right] /(6 \mathrm{EIL}) \quad 0 \leq \mathrm{x} \leq \mathrm{c}$

$\left(\delta_{\mathbf{C I}}\right)_{2}=$ the vertical displacement at $\mathrm{C}$ due to a unit load at $\mathrm{I}$, where, $\mathrm{I}$ is located anywhere between $\mathrm{C}$ and $\mathrm{D}$.

$\left(\delta_{\text {IC }}\right)_{2}=\left[\mathrm{c} *(\mathrm{x}-\mathrm{L}) *\left(\mathrm{x}^{3}+-2 \mathrm{xL}+\mathrm{c}^{2}\right)\right] /(6 \mathrm{EIL}) \quad \mathrm{a} \leq \mathrm{x} \leq \mathrm{L}$

By multiplying both sides of equation (5) by the inverse of the flexibility matrix we get:

$\mathbf{R}_{\mathbf{B}}=\mathbf{X}_{\mathbf{1}}=\left[1 /\left(\mathrm{F}_{11} * \mathrm{~F}_{22}-\mathrm{F}_{12} * \mathrm{~F}_{21}\right)\right] *\left(\mathrm{~F}_{22} * \delta_{\mathrm{IB}}-\mathrm{F}_{12} * \delta_{\mathrm{IC}}\right)$

$\mathbf{R}_{\mathbf{C}}=\mathbf{X}_{2}=\left[1 /\left(\mathrm{F}_{11} * \mathrm{~F}_{22}-\mathrm{F}_{12} * \mathrm{~F}_{21}\right)\right] *\left(\mathrm{~F}_{11} * \delta_{\mathrm{IC}}-\mathrm{F}_{12} * \delta_{\mathrm{IB}}\right)$

The solutions are represented graphically on the diagram shown below.

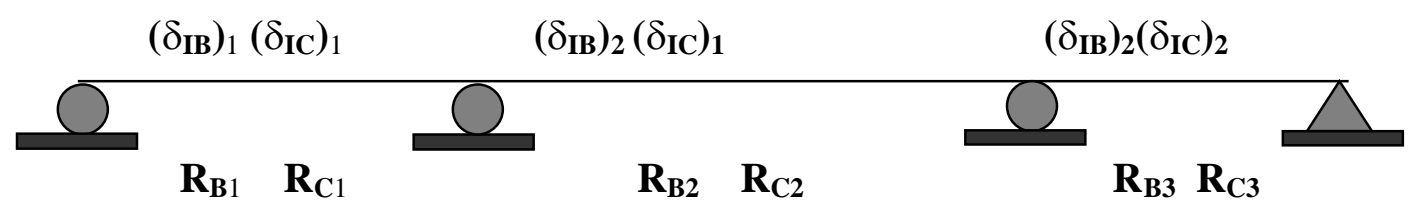

To solve for $\mathrm{R}_{\mathrm{B} 1}=$ substitute $\left(\delta_{\mathrm{IB}}\right)_{1}$ and $\left(\delta_{\mathrm{IC}}\right)_{1}$ in equation $(6)$.

To solve for $\mathrm{R}_{\mathrm{B} 2}=$ substitute $\left(\delta_{\mathrm{IB}}\right)_{2}$ and $\left(\delta_{\mathrm{IC}}\right)_{1}$ in equation (6).

To solve for $\mathrm{R}_{\mathrm{B} 3}=$ substitute $\left(\delta_{\mathrm{IB}}\right)_{2}$ and $\left(\delta_{\mathrm{IC}}\right)_{2}$ in equation (6).

To solve for $\mathrm{R}_{\mathrm{C} 1}=$ substitute $\left(\delta_{\mathrm{IB}}\right)_{1}$ and $\left(\delta_{\mathrm{IC}}\right)_{1}$ in equation (7).

To solve for $\mathrm{R}_{\mathrm{C} 2}=$ substitute $\left(\delta_{\mathbf{I B}}\right)_{2}$ and $\left(\delta_{\mathbf{I C}}\right)_{1}$ in equation (7).

To solve for $\mathrm{R}_{\mathrm{C} 3}=$ substitute $\left(\delta_{\mathbf{I B}}\right)_{2}$ and $\left(\delta_{\mathrm{IC}}\right)_{2}$ in equation (7).

Example \# 4:

Derive the equations for the influence lines for the reactions of the two-span continuous prismatic beam shown in figure E4.1.

The beam is statically indeterminate to the second degree, choose the bending moment at $\mathrm{A}$, and the vertical reaction at $B$, as the redundants. $X_{1}=M_{A}$, and $X_{2}=R_{B}$.

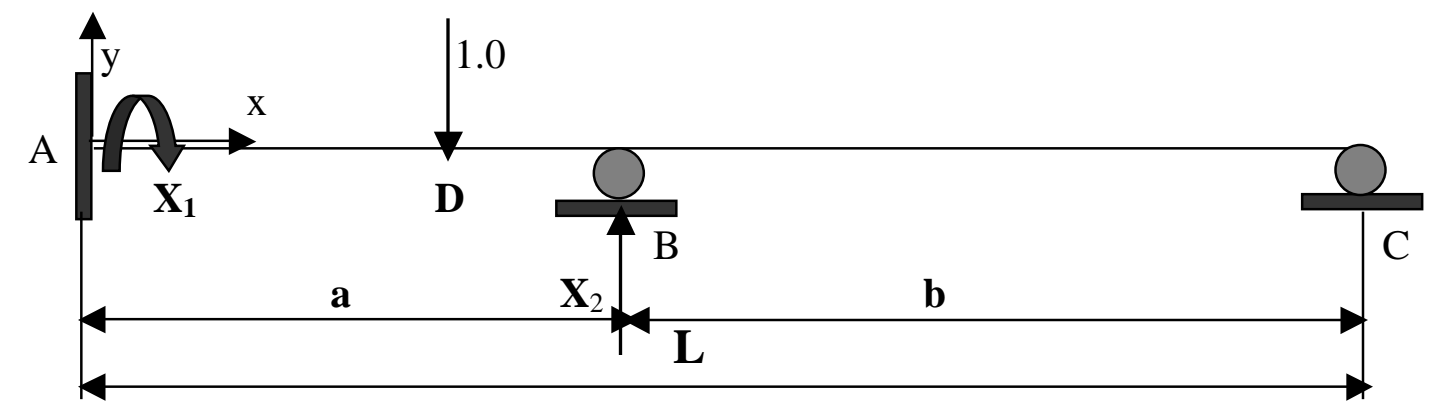

Figure E4.1. Two-span continuous beam fixed at one end

Proceeding of the 2002 American Society for Engineering Education Annual Conference \& Exposition Copyright () 2002, American Society for Engineering Education 
Remove the redundants, now, the beam is statically determinant as shown in figure E4.2.

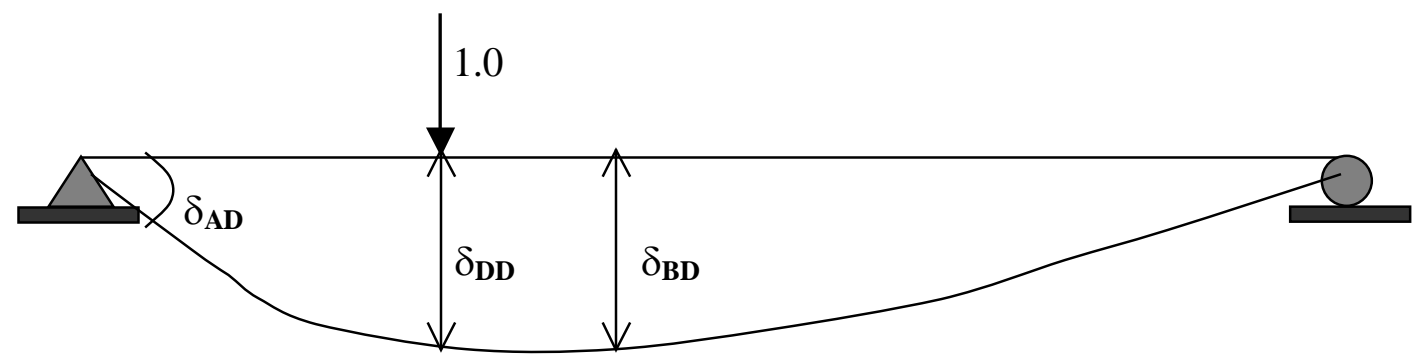

Figure E4.2. The released beam for example 4

Remove the applied load and apply a unit bending moment at A, as shown in figure E4.3.

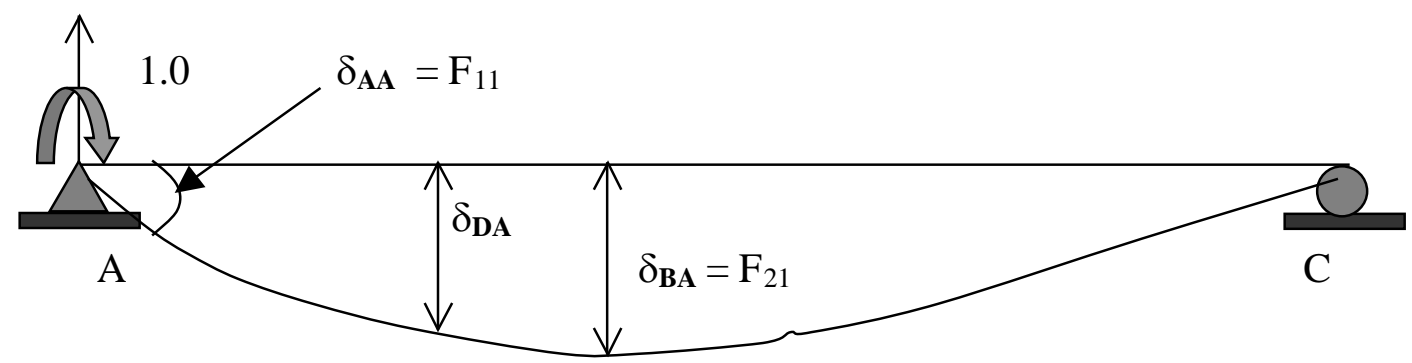

Figure E4.3. The virtual beam subjected to a unit bending moment at A

Apply a unit vertical load at B as shown in figure E4.4.

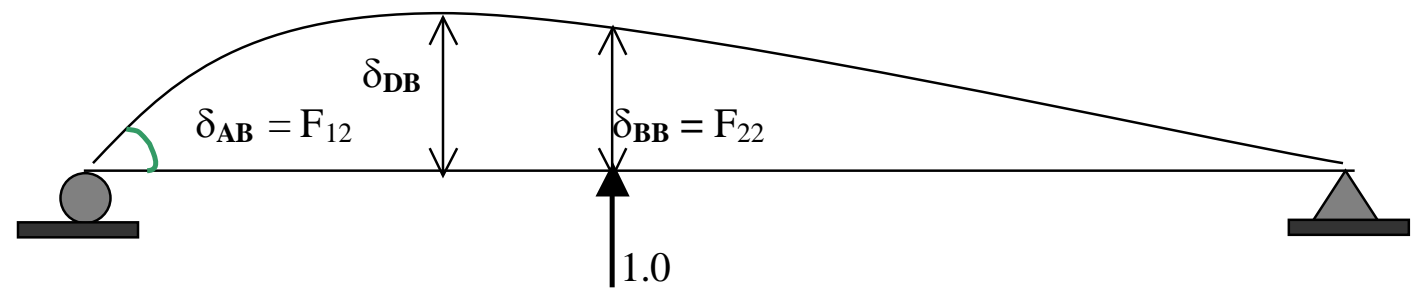

Figure E4.4. The virtual beam subjected to a unit vertical load at B

Making use of the principle of superposition, the relationship between the four previous figures can be represented by: Figure $(E 3.1)=$ Figure $(E 3.2)+$ Figure $(E 3.3) * X_{1}+$ Figure (3.4)* $\mathrm{X}_{2}$. Applying the compatibility conditions for the rotation at A, and the vertical displacement at B respectively, yield the equations shown below.

$0=\delta_{\mathrm{AD}}+\mathrm{F}_{11} \mathrm{X}_{1}-\mathrm{F}_{12} * \mathrm{X}_{2}$

$0=-\delta_{\mathrm{BD}}-\mathrm{F}_{21} \mathrm{X}_{1}+\mathrm{F}_{22} * \mathrm{X}_{2}$

Since we are dealing with unit load in figures E4.2, E4.3 and E4.4, we can set $\delta_{\mathbf{A D}}=\delta_{\mathbf{D A}}, \delta_{\mathbf{B D}}=$ $\delta_{\mathbf{D B}}$, and $\mathrm{F}_{12}=\mathrm{F}_{21}$.

In a matrix form the two equations can be represented by:

$$
\left[\begin{array}{ll}
F_{11} & -F_{12} \\
-F_{12} & F_{22}
\end{array}\right] \quad\left\{\begin{array}{l}
X_{1} \\
X_{2}
\end{array}\right\}=\left\{\begin{array}{l}
\delta_{D A} \\
-\delta_{D B}
\end{array}\right\}
$$

Proceeding of the 2002 American Society for Engineering Education Annual Conference \& Exposition Copyright $\odot$ 2002, American Society for Engineering Education 
$\mathrm{F}_{11}=$ rotation at $\mathrm{A}$ due to a unit bending moment at $\mathrm{A}$.

$\mathrm{F}_{22}=$ vertical displacement at $\mathrm{B}$ due to a unit vertical load at $\mathrm{B}$.

$\mathrm{F}_{12}=$ rotation at $\mathrm{A}$ due to a unit vertical load at $\mathrm{B}$.

$\mathrm{F}_{21}=$ vertical displacement at $\mathrm{B}$ due to a unit bending moment at $\mathrm{A}$.

$\delta_{\mathrm{DA}}=$ vertical displacement at any point $\mathrm{D}$ along the beam due to a unit bending moment at $\mathrm{A}$.

$\delta_{\mathrm{DB}}=$ vertical displacement at any point $\mathrm{D}$ along the beam due to a unit vertical load at $\mathrm{B}$

The parametric values of the above terms have been determined in the formulation of the influence lines for $\mathrm{R}_{\mathrm{B}}$ and $\mathrm{M}_{\mathrm{A}}$, in examples 1 , and 2 respectively.

$\mathrm{F}_{11}=\mathbf{2} * \mathbf{L}^{2} /(6 \mathrm{EIL}), \mathrm{F}_{22}=\mathbf{2} * \mathbf{a}^{2} \mathbf{b}^{2} /(6 \mathrm{EIL}), \mathrm{F}_{21}=\mathrm{F}_{12}=[\mathbf{a b} *(\mathbf{2 b}+\mathbf{a})] /(6 \mathrm{EIL})$

$\left(\delta_{\mathbf{D B}}\right)_{1}=$ the vertical displacement at any point $\mathrm{D}$, in figure $\mathrm{E} 4.4$ due to a unit vertical load at $\mathrm{B}$, where, $\mathrm{D}$ is located anywhere between $\mathrm{A}$ and $\mathrm{B}$.

$\left(\delta_{\text {DB }}\right)_{1}=\left[-\mathrm{bx}^{3}+\mathrm{ab} * \mathrm{x} *(\mathrm{a}+2 \mathrm{~b})\right] /(6 \mathrm{EIL}) \quad 0 \leq \mathrm{x} \leq \mathrm{a}$

$\left(\delta_{\mathbf{D B}}\right)_{2}=$ the vertical displacement at any point $\mathrm{D}$, in figure E4.4 due to a unit vertical load at B, where, $\mathrm{D}$ is located anywhere between $\mathrm{B}$ and $\mathrm{C}$.

$\left(\delta_{\mathrm{DB}}\right)_{2}=\left[\mathrm{a} *(\mathrm{x}-\mathrm{L}) *\left(\mathrm{x}^{2}-2 \mathrm{xL}+\mathrm{a}^{2}\right)\right] /(6 \mathrm{EIL}) \quad \mathrm{a} \leq \mathrm{x} \leq \mathrm{L}$

$\left(\delta_{\mathbf{D A}}\right)=$ the vertical displacement at any point $\mathrm{D}$, in figure $\mathrm{E} 4.3$, due to a unit bending moment at $\mathrm{A}$, where, $\mathrm{D}$ is located anywhere along the beam.

$\left(\delta_{\text {DA }}\right)=\left(-\mathrm{x}^{3}+3 \mathrm{x}^{2} \mathrm{~L}-2 \mathrm{~L}^{2} \mathrm{x}\right) /(6 \mathrm{EIL}) \quad 0 \leq \mathrm{x} \leq \mathrm{L}$

By multiplying both sides of equation (10) by the inverse of the flexibility matrix we get:

$\mathbf{M}_{\mathrm{A}}=\mathbf{X}_{1}=\left[1 /\left(\mathrm{F}_{11} * \mathrm{~F}_{22}-\mathrm{F}_{12} * \mathrm{~F}_{21}\right)\right]^{*}\left(\mathrm{~F}_{22} * \delta_{\mathrm{DA}}-\mathrm{F}_{12} * \delta_{\mathrm{DB}}\right)$

$\mathbf{R}_{\mathbf{B}}=\mathbf{X}_{\mathbf{2}}=\left[1 /\left(\mathrm{F}_{11} * \mathrm{~F}_{22}-\mathrm{F}_{12} * \mathrm{~F}_{21}\right)\right] *\left(\mathrm{~F}_{12} * \delta_{\mathrm{DA}}-\mathrm{F}_{11} * \delta_{\mathrm{DB}}\right)$

The explicit parametric representation of $\mathrm{M}_{\mathrm{A}}$, and $\mathrm{R}_{\mathrm{B}}$ are cumbersome.

The solutions are represented graphically on the diagram shown below.

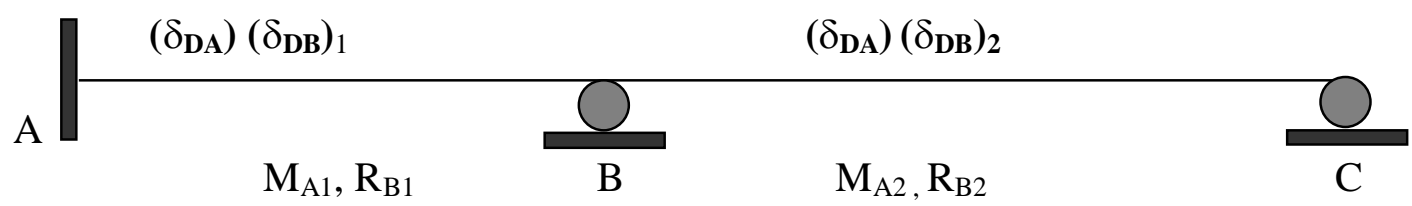

To solve for $\mathrm{M}_{\mathrm{A} 1}=$ substitute $\left(\delta_{\mathbf{D A}}\right)$ and $\left(\delta_{\mathrm{DB}}\right)_{1}$ in equation (11).

To solve for $\mathrm{M}_{\mathrm{A} 2}=$ substitute $\left(\delta_{\mathrm{DA}}\right)$ and $\left(\delta_{\mathrm{DB}}\right)_{2}$ in equation (11).

To solve for $\mathrm{R}_{\mathrm{B} 1}=$ substitute $\left(\delta_{\mathrm{DA}}\right)$ and $\left(\delta_{\mathrm{DB}}\right)_{1}$ in equation $(12)$.

To solve for $\mathrm{R}_{\mathrm{B} 2}=$ substitute $\left(\delta_{\mathbf{D A}}\right)$ and $\left(\delta_{\mathbf{D B}}\right)_{2}$ in equation $(12)$.

As proven by the two previous examples the influence lines for multi-span beams with various support conditions, can be developed by using the solutions from examples 1 and 2 . The students in the Advanced Structural Analysis course have been using the procedures presented in this paper to create their own programs to obtain the solutions for the influence lines for many multi-span beams, with different boundary conditions. 


\section{Conclusion}

The mathematical model of influence lines for indeterminate beam has been presented. The mathematical model offers a new and simple approach to construct the influence lines for indeterminate beams. The mathematical manipulations involved in the derivation of the solution of multi-span beam are cumbersome. It was proven in examples 3 and 4, that the parametric derivations presented in examples 1 and 2 can be used to develop the solutions for multi-span beams. Student response to the implementation of the mathematical model into a structural analysis has been outstanding. After dealing with multi-span beams, several students suggested removing the word "simple" from the new approach and replacing it with the word "complex". Many students have developed their own computer programs to solve the problems of influence lines for indeterminate beams. The majority of the programs have been developed using spreadsheet packages. These programs are being used in graduate classes dealing with long span structures. The student evaluations of the new approach showed their appreciation of the use of mathematics in their civil engineering courses. The new approach is an excellent method to cover the topic of influence lines for indeterminate beams.

\section{References}

1- R.C Hibbeler, Structural Analysis, fourth edition, Prentice-Hall, NJ, 1998

2- Harry H. West, Analysis of Structures, John Wiley, NY 1993

3- Alexander Chajes, Structural Analysis, Prentice-Hall, NJ, 1990

4- Louis C. Tartaglione, Structural Analysis, McGraw-Hill, NY, 1991

5- Ronald L. Sack, Structural Analysis, McGraw-Hill, NY, 1984

6- Aslam Kassimali, Structural Analysis, second edition, PWS, NY 1999

7- William Waever, Matrix Analysis of Framed Structures, third edition, Van Nostrand, NY, 1990.

\section{Biography}

Dr. MOUJALLI HOURANI is an associate professor of civil engineering at Manhattan College in New York. Dr. Hourani received his bachelor's degree from Manhattan College, a master degree from Rose Hulman Institute of Technology, and Doctor of Science degree from Washington University. Dr. Hourani's research experience includes: composite materials, finite elements, and reinforced concrete. 